\title{
The transition of ethanol flames from conventional to MILD combustion
}

\author{
Jingjing Ye ${ }^{\mathrm{a}, *}$, Paul R. Medwell ${ }^{\mathrm{a}}$, Bassam B. Dally ${ }^{\mathrm{a}}$, Michael J. Evans ${ }^{\mathrm{a}}$ \\ ${ }^{a}$ School of Mechanical Engineering, The University of Adelaide, South Australia 5005, Australia
}

\begin{abstract}
The present paper is focused on prevaporised ethanol flames in the transition from conventional combustion to the MILD combustion regime. Photographs and imaging of $\mathrm{OH}^{*}$ chemiluminescence reveal a distinctive flame structure when ethanol carried by air burns in a $3 \% \mathrm{O}_{2}$ coflow (typical of MILD combustion), differing from that at higher oxygen levels. In comparison to flames carried by air in a $9 \% \mathrm{O}_{2}$ coflow, the spatial gradient and the peak in the $\mathrm{OH}^{*}$ signal profile are significantly reduced in the $3 \% \mathrm{O}_{2}$ coflow, indicating a more uniform distribution of heat release and temperature. The use of $\mathrm{N}_{2}$ as a carrier gas renders the $\mathrm{OH}^{*}$ profile for the $6 \% \mathrm{O}_{2}$ coflow case similar to that of flames carried by air in the $3 \% \mathrm{O}_{2}$ coflow. The experimental results indicate a transition from conventional combustion to MILD combustion with the decrease of coflow $\mathrm{O}_{2}$ level and/or the use of $\mathrm{N}_{2}$ as a carrier gas. Calculations reveal that a substantial drop in the peak heat release rate and/or overall net heat release rate might contribute to the lack of luminosity of flames in the $3 \% \mathrm{O}_{2}$ coflow, suggesting a need for threshold values of these two in defining MILD combustion. A series of laminar flame calculations are performed to identify the MILD combustion regime based on the absence of a negative heat release region. The absence of a negative heat release region is found to be strain rate dependent at a given temperature and $\mathrm{O}_{2}$ level of the oxidant stream. This is mainly a result of the enhanced transportation of $\mathrm{O}_{2}$ across the reaction zone at a higher strain rate. At low strain rates, the negative heat release region is more likely to disappear in a $3 \% \mathrm{O}_{2}$ oxidant flow due to a combination of low flame temperature and high availability of $\mathrm{O}_{2}$.
\end{abstract}

Keywords: MILD combustion, prevaporised ethanol, carrier gas

\section{Introduction}

A large body of work has been published on Moderate or Intense Low-oxygen Dilution (MILD) combustion due to its capacity to reduce emissions and maintain high thermal efficiency [1, 2, 3, 4, 5. In practice, MILD combustion is achieved through enhanced mixing of hot exhaust gases with reactants, which creates a hot oxygen-deficient environment. According to a MILD combustion regime map summarised by Rao and Levy [6], the local oxygen concentration is around $3 \%-12 \%$, and the temperature of the reactants is above the autoignition temperature. This environment creates a semi-uniform temperature distribution with a

\footnotetext{
* Corresponding author

Email address: jingjing.ye01@adelaide.edu.au (Jingjing Ye)
} 
lower peak flame temperature, which significantly reduces the emissions of $\mathrm{NO}_{x}$ and soot [5, 7, 8, These characteristics of MILD combustion are highly desired in many industrial applications. For instance, a larger radiating volume and a higher net radiation flux, resulting from volumetric reactions under MILD combustion conditions, are favoured in furnaces and boilers [2]. This high radiant flux is not necessarily advantageous when it comes to application in gas turbines, where excessive heating of the walls may lead to material degradation. However, due to a semi-uniform temperature distribution with a lower peak temperature under MILD combustion conditions, a higher efficiency can be achieved by raising the mean temperature of products, while maintaining low $\mathrm{NO}_{x}$ formation and the durability of gas-turbine components.

A configuration of a jet in a hot and diluted coflow is commonly adopted to facilitate the experimental study of MILD combustion as the temperature and oxygen concentration of the coflow can be adjusted independently to mimic MILD combustion conditions [9, 10]. However, several differences in the flame structure and behaviour on simple gaseous fuels were reported in previous studies [7, 9, 10, 11, 12, 13, 14, even though those experiments were all defined as MILD combustion based on the regime map by Rao and Levy [6]. For instance, the liftoff heights of jet flames in various hot and diluted coflow responded differently to changes in the same parameter, indicating differences in the jet stabilization mechanism [10, 11, 12. Particularly, Oldenhof et al. [10, 11] reported that the liftoff height initially reduced with increasing jet velocity or Reynolds number in a hot coflow with $7.6 \%-8.8 \% \mathrm{O}_{2}$ by mass, which was consistent with experimental studies in the Jet in Hot Coflow (JHC) burner [7. These measurements contradict measurements of liftoff heights reported by Cabra et al. [12, which is probably caused by a higher $\mathrm{O}_{2}$ level in the coflow $\left(\mathrm{X}_{\mathrm{O}_{2}} \geq\right.$ $12 \%)$. Another phenomenon observed in flames burning in the JHC burner, differing from conventional lifted flames, was that liftoff heights increased with coflow temperature or oxygen level [13. This unusual behaviour was attributed to the transition from MILD combustion regime to the conventional combustion regime [13]. Indeed, significant differences in the jet stabilization mechanism occur as coflow $\mathrm{O}_{2}$ concentration changes. Gordon et al. 14 proposed that lifted flames in a hot coflow are stabilized by a build-up of ignition kernels. They classified the evolution of autoignition for methane flames in a hot coflow with $11 \%$ to $12 \% \mathrm{O}_{2}$ by volume into three stages: $\mathrm{CH}_{2} \mathrm{O}$ only, $\mathrm{OH}$ formation, $\mathrm{CH}_{2} \mathrm{O}$ consumption and formation of a steady lifted flame [14. In particular, $\mathrm{CH}_{2} \mathrm{O}$ reached its maximum before ignition, then it was consumed after ignition 14. However, the formation of $\mathrm{OH}$ peaked at ignition, and those peaks were maintained in the lifted flame [14. When the mole fraction of $\mathrm{O}_{2}$ was reduced to $3 \%, \mathrm{CH}_{2} \mathrm{O}$ was found to play the same role as an ignition precursor, while an $\mathrm{OH}$ tail was found to extend to the jet exit plane, indicating an attached flame [7. Similar phenomenon was reported in a numerical study by Sidey et al. [15. They found that as the mixture became more diluted, the initial pre-ignition reaction merged with the primary ignition reaction such that the sharp rise in the temperature profile disappeared [15].

To understand the transition from conventional combustion to MILD combustion, Medwell et al. 13. performed comprehensive experiments on methane- and ethylene- based flames, including a wide range of jet Reynolds number, coflow oxygen concentration and temperature. The present study is a follow-up study on this topic, which is part of a larger programme. Instead of alkanes, the present study investigates ethanol flames. Ethanol can be produced from renewable energy sources, such as sugar-cane and corn. It has a low 
tendency to generate soot and particulate matter. In addition, ethanol can be burnt at very lean conditions because of its high flame speed [16, which produces a lower flame temperature, thereby reducing $\mathrm{NO}_{x}$ and $\mathrm{CO}$ emissions. Moreover, a previous study by Rodrigues et al. 17] found that the occurrence of high ethanol flame temperature was significantly suppressed under MILD combustion conditions in comparison to that in conventional combustion conditions, which could help abate $\mathrm{NO}_{x}$ and $\mathrm{CO}$ emissions further.

In the present study, ethanol is prevaporised before injection to avoid the complicated coupling effects of fuel chemistry and spray characteristics. In this case, heated gas is required as a carrier to help deliver prevaporised ethanol and prevent it from condensing. The choice of carrier gas, such as air or $\mathrm{N}_{2}$, has been reported to affect the temperature distribution and the flame structure in spray burners [18, 19, and change the $\mathrm{NO}_{x}$ formation in a reverse-flow MILD combustor [20]. In addition, previous work 21] has shown that the enhanced $\mathrm{O}_{2}$ diffusion towards the fuel-rich side through "reaction zone weakening" is a key feature of MILD combustion flames, leading to an increasing formation of important intermediates. The build-up of those intermediates is responsible for the stabilization of the flames [21. Adding a small amount of $\mathrm{O}_{2}$ to the fuel stream is suspected to produce similar effects. Although $\mathrm{N}_{2}$ is unlikely to be used for fuel atomisation or delivery in industrial applications, part of the hot exhaust gases are expected to provide the preheating and dilution of liquid fuels when MILD combustion of liquid fuels is commercialised. The exhaust gas is composed of oxidiser and inert, which is represented by air and $\mathrm{N}_{2}$, respectively. It is important to understand the impact of those species in the exhaust gas. By switching air and $\mathrm{N}_{2}$ alternatively as a carrier gas in a JHC burner, this issue can be explored in a controlled and simplified environment.

In summary, this paper aims to improve the understanding of the transition from conventional combustion to MILD combustion. Due to the potential advantages of applying MILD combustion to ethanol flames, this paper is focused on the transition of prevaporised ethanol flames in a hot diluted coflow, the understanding of which can provide guidance to establish MILD combustion of ethanol when it is commercialised. Images of $\mathrm{OH}^{*}$ chemiluminescence are collected from prevaporised ethanol flames issuing into a JHC burner to reveal the impact of carrier gas, jet velocity and coflow oxygen concentration. A series of laminar flame calculations are performed to provide additional insights into the experimental observations.

\section{Experimental Details}

\subsection{Experimental Setup and Operating Conditions}

The basic configuration and operation of this JHC burner shown in Figure 1 are the same as a previous study [7]. The JHC burner consists of an air-cooled central fuel jet ( $\mathrm{ID}=4.6 \mathrm{~mm}$ ) in a coflow of hot exhaust products from a secondary porous-bed burner ( $\mathrm{ID}=82 \mathrm{~mm}$ ) located $90 \mathrm{~mm}$ upstream of the jet exit plane. The hot coflow is produced from the combustion of a lean mixture of natural gas, air, $\mathrm{H}_{2}$ and $\mathrm{N}_{2}$. The mole fractions of natural gas, air, $\mathrm{H}_{2}$ and $\mathrm{N}_{2}$ are manipulated to generate $3 \%-11 \%$ oxygen by volume in the hot coflow, while the $\mathrm{C} / \mathrm{H}$ ratio is kept constant. The temperature for the various coflow conditions $\left(\mathrm{T}_{\text {coflow }}\right)$ varies from $1250 \mathrm{~K}$ to $1385 \mathrm{~K}$. To obtain fully developed turbulent pipe flow, the length of the central fuel jet is more than 100 times the jet diameter. The burner is wrapped with ceramic fibre insulation to minimise heat losses and maintain a constant temperature of the coflow. 


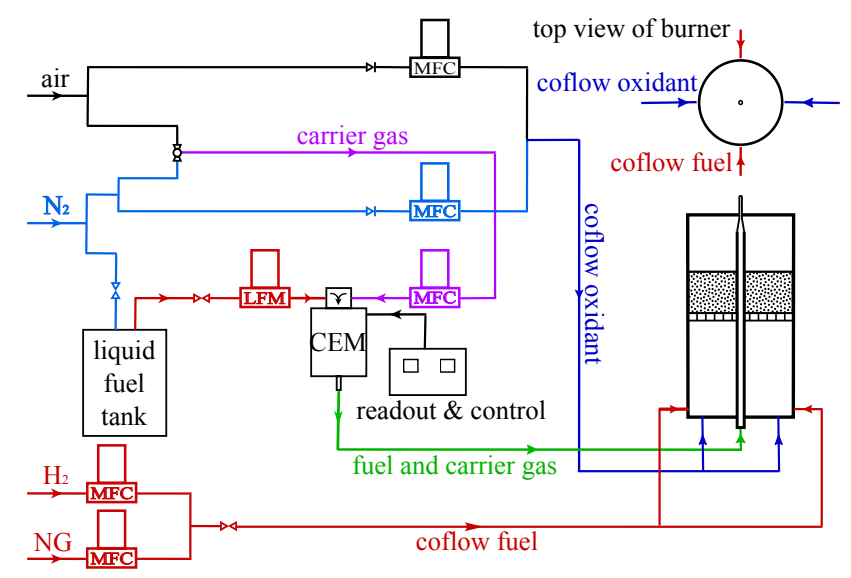

Figure 1: Experimental Setup: CEM is the Controlled Evaporator and Mixer, MFC is the mass flow controller for gases, and LFM is the liquid flow meter.

As shown in Figure 1, ethanol is heated and mixed with carrier gas in a Controlled Evaporator and Mixer (CEM). The temperature of the heater inside the CEM is set by the Bronkhorst control unit, which also controls the mass flow rates of ethanol and carrier gas. The preheat temperature is set to $413 \mathrm{~K}$, which is higher than the boiling point of ethanol to prevent condensation along the pipeline. After prevaporisation, the mixture of ethanol and carrier gas is fed into the JHC burner via the central fuel jet. Note that when switching between air and $\mathrm{N}_{2}$ as a carrier gas, the flow rates of ethanol and carrier gas are kept constant. For the baseline case (F10-A1), the jet Reynolds number and the bulk jet velocity are kept around 10,000 and $44 \mathrm{~m} / \mathrm{s}$, respectively. Due to the lower viscosity and density of $\mathrm{N}_{2}$, the jet Reynolds number of ethanol carried by $\mathrm{N}_{2}$ is $1 \%$ higher than that of ethanol carried by air, while the bulk jet velocity is $2 \%$ higher. Table 1 shows all the fuel jet conditions investigated in the present paper. As shown in Table 1, low (F10-A1) and high jet Reynolds number cases (F30-A1) are performed to investigate the impact of jet Reynolds number. Cases denoted by F10-A3 and F10-N3 are performed to study the impact of carrier gas. The mole fraction of carrier gas in the fuel jet is 0.67 in F10-A3 and F10-N3 cases, which is higher than that in the baseline case to magnify the differences caused by carrier gases. It is worth mentioning that though air is added to the fuel jet, those flames are not partially premixed flames. A plethora of literature, for example, a study by Stårner et al. 22], has shown that flames with air dilution of the fuel up to $77 \%$ by volume behave like non-premixed flames. Hence, the comparison between these different carrier gases cases is valid. In addition, it has been validated by simulations that no reactions occur before the fuel stream is fed to the burner. Table 2 shows the stoichiometric mixture fraction $\left(\mathrm{Z}_{s t}\right)$ for a given combination of coflow and fuel jet conditions.

Imaging of the flames is achieved both through conventional photography and $\mathrm{OH}^{*}$ chemiluminescence, which is detected with an electronically gated pco.pixelfly camera equipped with a Lambert Instruments intensifier. The camera system is coupled to a $50 \mathrm{~mm} \mathrm{f} / 3.5 \mathrm{UV}$ transmissive lens and a $310 \mathrm{~nm}$ bandpass optical filter with a bandwidth of $10 \mathrm{~nm}$. The photographs of the flames are taken using a Canon EOS 60D SLR camera with a standard $50 \mathrm{~mm} \mathrm{f/1.8} \mathrm{lens.}$ 


\begin{tabular}{cccc}
\hline & $\mathrm{Re}_{j e t}$ & Carrier gas & $\mathrm{X}_{\text {carrier }}$ \\
\hline F10-A1 & 10,000 & air & 0.59 \\
F30-A1 & 30,000 & air & 0.59 \\
F10-A3 & 10,000 & air & 0.67 \\
F10-N3 & 10,000 & $\mathrm{~N}_{2}$ & 0.67 \\
\hline
\end{tabular}

Table 1: List of fuel jet conditions: $\mathrm{X}_{\text {carrier }}$ indicates the mole fraction of carrier gas in the fuel jet

\begin{tabular}{cccc}
\hline $\mathrm{O}_{2}$ in the coflow & F10-A1 & F10-A3 & F10-N3 \\
\hline $3 \%$ & 0.0342 & 0.0427 & 0.0362 \\
$6 \%$ & 0.0669 & 0.0828 & 0.0706 \\
$9 \%$ & 0.0964 & 0.1184 & 0.1015 \\
$11 \%$ & 0.1138 & 0.1392 & 0.1198 \\
\hline
\end{tabular}

Table 2: Stoichiometric mixture fraction $\left(\mathrm{Z}_{s t}\right)$ for various fuel jets in the coflow with $3 \%-11 \% \mathrm{O}_{2}$ by volume

\subsection{The Use of $O H^{*}$ chemiluminescence in MILD Combustion}

The chemiluminescence of $\mathrm{OH}^{*}$ is a natural emission of light within the flame when excited $\mathrm{OH}$ relaxes from an upper electronic state to a lower electronic state. It is known that $\mathrm{OH}^{*}$ has a short lifetime and its formation requires high energy [23]. Previous studies [24, 25] have shown that the intensity of $\mathrm{OH}^{*}$ chemiluminescence can be used as an indicator of the reaction zone and the heat release rate in lean premixed flames.

In order to interpret the intensity of $\mathrm{OH}^{*}$ chemiluminescence confidently under MILD combustion conditions, laminar flame calculations are performed for ethanol flames with the OPPDIF code in the Chemkin software. The full multi-component formulation as well as thermal diffusion are included in calculations. As most previous studies using $\mathrm{OH}^{*}$ imaging were performed for premixed flames [24, 25], a non-premixed case with pure ethanol in the fuel stream is included in calculations to account for non-premixed flames in the current experiments. A partial premixed case is performed for comparison, in which the fuel jet is modelled as $50 \%$ of ethanol and $50 \%$ of air (by volume). The stoichiometric mixture fraction in the non-premixed case and partially premixed case is 0.0164 and 0.0283 , respectively. Calculations are performed for various oxygen concentrations and inlet velocities (strain rates), which show the same trend. Hence, only results for flames in the oxidant stream with $3 \% \mathrm{O}_{2}$ at a fuel inlet velocity of $0.8 \mathrm{~m} / \mathrm{s}$ and an oxidiser inlet velocity of $1.68 \mathrm{~m} / \mathrm{s}$ are presented here. Note that the velocities of the two opposed flows are set in a way that their jet momentum flow rates balance at the midpoint between the two inlets in all the laminar flame calculations in this paper. The distance between the two opposed nozzles is $20 \mathrm{~mm}$. The chemical kinetic mechanism used includes the ethanol chemical kinetic mechanism developed by Marinov [26] and $\mathrm{OH}^{*}$ kinetics provided in 27] and [28.

Figure 2 displays the profiles of normalised temperature, number density of $\mathrm{OH}^{*}\left(\mathrm{n}_{\mathrm{OH}^{*}}\right)$ and heat production rate (HPR) in mixture fraction space for ethanol flames burning in a 1250-K oxidiser, in which the location of the stoichiometric mixture fraction is indicated by a vertical dotted line. Note that a previous study found that the number density of $\mathrm{OH}^{*}$ obtained from laminar flame calculations agreed well with the measured chemiluminescence of $\mathrm{OH}^{*}[29$. The heat production rate here is defined as the net heat production rate from gas-phase reactions per unit volume. It can be seen that $\mathrm{OH}^{*}$ and most of the heat is produced within the high temperature region, which falls on the oxidiser side. In addition, the location of the peak $\mathrm{n}_{\mathrm{OH}^{*}}$ and HPR closely matches with the location of peak flame temperature. The correlation between $\mathrm{OH}^{*}$ 


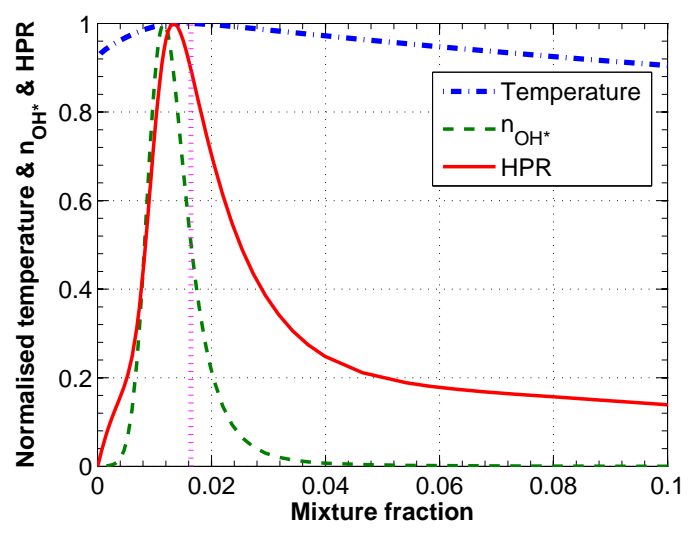

(a) non-premixed case

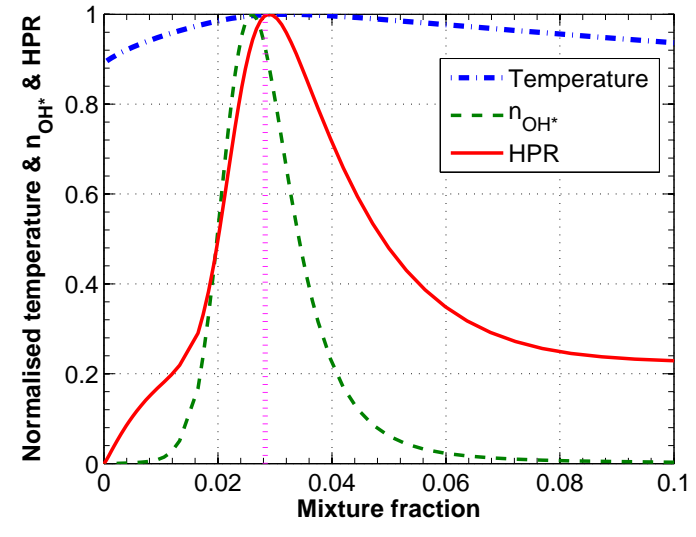

(b) partially premixed case

Figure 2: Normalised temperature, number density of $\mathrm{OH}^{*}\left(\mathrm{n}_{\mathrm{OH}^{*}}\right)$ and heat production rate (HPR) as a function of mixture fraction for ethanol flames in a 1250-K oxidiser with $3 \% \mathrm{O}_{2}$ : (a) non-premixed case; (b) partially premixed case. The vertical dotted line indicates the location of the stoichiometric mixture fraction.

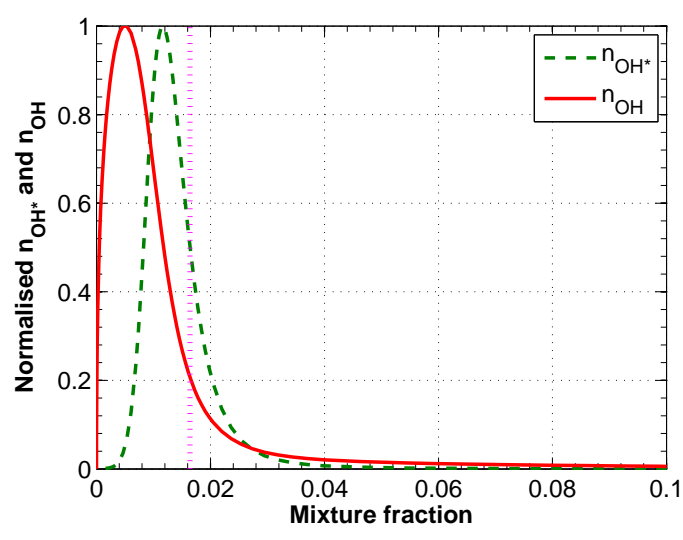

(a) non-premixed case

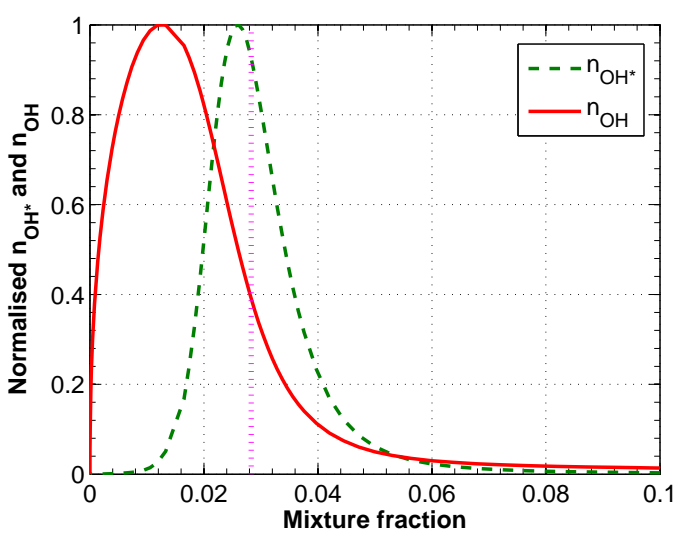

(b) partially premixed case

Figure 3: Normalised number density of $\mathrm{OH}^{*}\left(\mathrm{n}_{\mathrm{OH}^{*}}\right)$ and $\mathrm{OH}\left(\mathrm{n}_{\mathrm{OH}}\right)$ as a function of mixture fraction for ethanol flames in a 1250-K oxidiser with $3 \% \mathrm{O}_{2}$ : (a) non-premixed case; (b) partially premixed. The vertical dotted line indicates the location of the stoichiometric mixture fraction.

and HPR was also reported in a simulation of non-premixed methane flames in hot diluted coflow [30. However, it is shown in Figure 3 that the location of peak $\mathrm{n}_{\mathrm{OH}^{*}}$ fails to coincide with the location of peak $\mathrm{n}_{\mathrm{OH}}$. This is supported by OH-PLIF measurements in MILD combustion of methane in a cross-flow configuration, which demonstrates that $\mathrm{OH}$ was formed in the absence of heat release, as indicated by the lack of $\mathrm{OH}^{*}$ chemiluminescence [31. The phenomena described above are observed in both the partially premixed and non-premixed cases. Therefore, $\mathrm{OH}^{*}$ chemiluminescence can be used as an indicator of high temperature and heat production rate region, though it does not necessarily correlate with the number density of $\mathrm{OH}$ particularly well. 


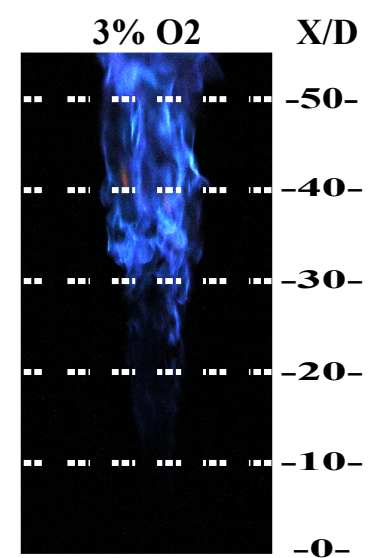

(a)

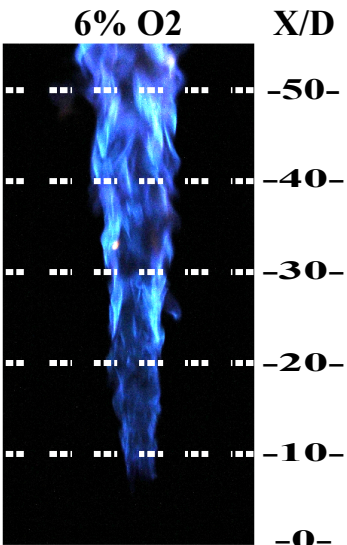

(b)

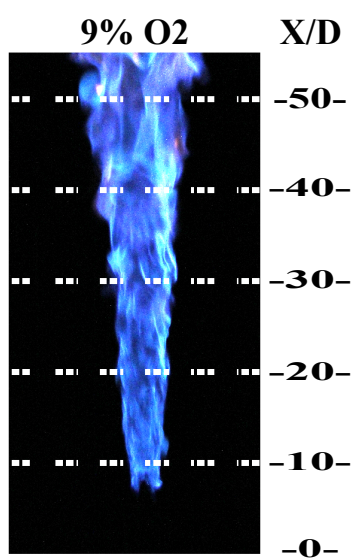

(c)
$11 \% \mathrm{O} 2$

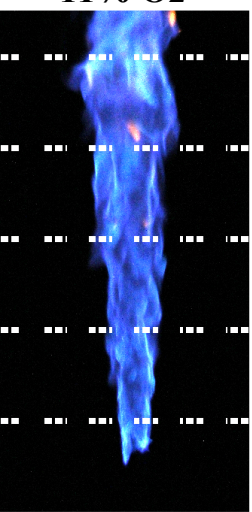

(d)

Figure 4: Photographs of ethanol flames carried by air (F10-A1) at a $1250-\mathrm{K}$ coflow with $3-11 \% \mathrm{O}_{2}$ by volume. The region shielded by coflow is up to $\mathrm{X} / \mathrm{D}=22$, where $\mathrm{X}$ is the axial distance above the jet and $\mathrm{D}$ is the jet diameter.

\section{Results}

\subsection{Impact of Coflow Oxygen Concentration}

To investigate the impact of coflow oxygen concentration on the transitional behaviour, experiments are performed with ethanol carried by air (F10-A1) in a 1250-K coflow. Figure 4 displays photographs of the ethanol flames carried by air under the four coflow conditions $\left(3,6,9\right.$, and $11 \% \mathrm{O}_{2}$ by volume). The bottom edge of all the photographs coincides with the jet exit plane. All the photographs in this section are taken with an ISO sensitivity of 1600, exposure time of 1 millisecond and an f-number of 2 .

The surrounding air entrainment has an affect on the flame above $100 \mathrm{~mm}$ downstream the jet exit plane $(\mathrm{X} / \mathrm{D}=22$, where $\mathrm{X}$ is the axial distance above the jet and $\mathrm{D}$ is the jet diameter) [32]. The impact of cold air entrainment on the reaction zone has been discussed in a previous study [32, hence the present study only focuses on the region shielded by the hot coflow. Flames in the $9 \% \mathrm{O}_{2}$ and $11 \% \mathrm{O}_{2}$ coflow are very similar, which appear as typical lifted jet flames. Those flames in $9 \% \mathrm{O}_{2}$ and $11 \% \mathrm{O}_{2}$ coflow show a clear flame base, and a continuous flame sheet downstream of the base. The luminosity of flames, within the region controlled by the hot coflow, reduces significantly with coflow oxygen level. Particularly, the luminosity of ethanol flame in the $3 \% \mathrm{O}_{2}$ coflow is so low that it appears lifted in the photograph. However, a previous study on the same JHC burner [7] has reported the existence of $\mathrm{OH}$ and $\mathrm{CH}_{2} \mathrm{O}$ kernels in ethylene flames in a $3 \% \mathrm{O}_{2}$ coflow, though photographs of those flames also suggested that they were lifted. In addition, the detection of $\mathrm{OH}^{*}$ chemiluminescence in the apparently lifted region $(\mathrm{X} / \mathrm{D}<20)$ of ethanol flames in the current experiments suggest reactions in fact occurs, which is shown in Fig. 5 . The lack of luminosity is in line with the common observation that MILD combustion is "flameless" [2, 5, 33. The flame base in the 6\% $\mathrm{O}_{2}$ coflow is less clear in comparison to that in the $9 \% \mathrm{O}_{2}$ coflow, though it is much more discernible than that in the $3 \% \mathrm{O}_{2}$ coflow.

The differences in the flame structure under various coflow conditions are also observed in $\mathrm{OH}^{*}$ images. Figure 5 displays the $\mathrm{OH}^{*}$ chemiluminescence images. The intensity of the $\mathrm{OH}^{*}$ chemiluminescence from ethanol flames in a $3 \% \mathrm{O}_{2}$ coflow is fairly weak, and it gradually reduces towards the jet exit plane. However, 


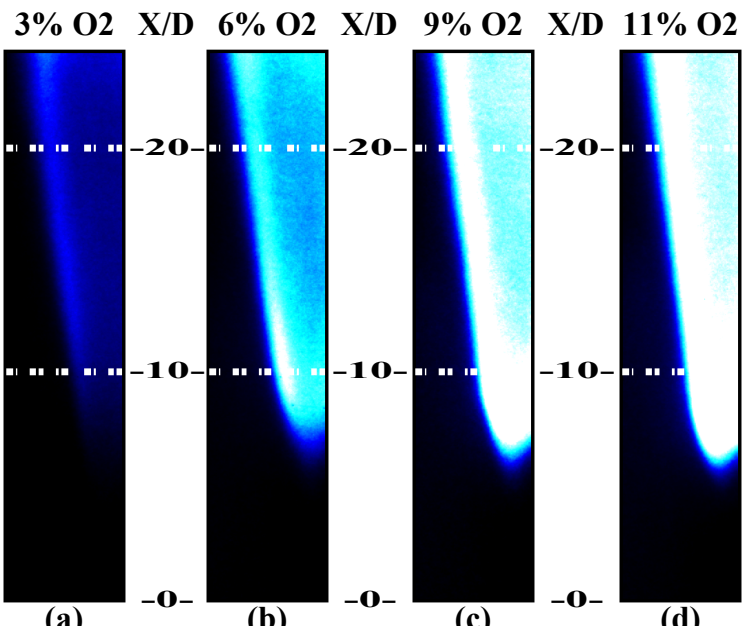

(a)

(b)

(c)

(d)

Figure 5: Averaged $\mathrm{OH}^{*}$ images (left-hand side of jet centreline) of ethanol flames carried by air (F10-A1) at a 1250-K coflow with $3-11 \% \mathrm{O}_{2}$ by volume.

a clear base is discernible for flames in $9 \% \mathrm{O}_{2}$ and $11 \% \mathrm{O}_{2}$ coflow. Figure 6 presents the peak $\mathrm{OH}^{*}$ signal for various coflow conditions. The peak $\mathrm{OH}^{*}$ signal presented refers to the maximum $\mathrm{OH}^{*}$ signal at a given height in the averaged image after background correction, which is in arbitrary units.

The intensity of $\mathrm{OH}^{*}$ chemiluminescence in the flame increases significantly with the coflow oxygen level. This observation is different from a previous study on MILD combustion in jets in cross-flow 31, which reported that the oxygen level had little impact on the intensity of $\mathrm{OH}^{*}$ chemiluminescence. However, these two findings are not contradictory as at a lower oxygen level, the adiabatic flame temperature of the coflow was increased in the previous study rather than being kept constant. The build-up of OH* also changes significantly with the coflow oxygen level. For flames carried by air in the $9 \%$ and $11 \% \mathrm{O}_{2}$ coflow, three distinguishable regions are formed: in the first region no chemiluminescence is produced; in the second region a rapid production of $\mathrm{OH}^{*}$ occurs, where the intensity of $\mathrm{OH}^{*}$ chemiluminescence peaks; in the third region a decline in the intensity of $\mathrm{OH}^{*}$ chemiluminescence is apparent. However, in a $3 \% \mathrm{O}_{2}$ coflow, there is neither a rapid build-up of $\mathrm{OH}^{*}$ nor a decrease in the intensity of $\mathrm{OH}^{*}$ chemiluminescence. Instead, the intensity of $\mathrm{OH}^{*}$ chemiluminescence increases gradually with the axial distance in the $3 \% \mathrm{O}_{2}$ coflow. This suggests that the flame temperature becomes more spatially distributed in a more diluted coflow. Moreover, heat is produced more distributively in the $3 \% \mathrm{O}_{2}$ coflow due to the close correlation of $\mathrm{OH}^{*}$ and heat production rate. The $\mathrm{OH}^{*}$ profile for flames in the $6 \% \mathrm{O}_{2}$ coflow show features in between the $3 \% \mathrm{O}_{2}$ coflow and the $9 \% \mathrm{O}_{2}$ coflow. Due to the distributed nature of MILD combustion, the $\mathrm{OH}^{*}$ profile in the $6 \% \mathrm{O}_{2}$ coflow signals a transition from MILD combustion to conventional combustion, which is consistent with experimental observation in the previous study of gaseous fuels [13].

\subsection{Impact of Carrier Gas}

In order to investigate the impact of carrier gas, air or nitrogen is used as a carrier gas to deliver prevaporised ethanol. The mole fraction of carrier gas in the fuel jet is 0.67 in this set of experiments (F10-A3/F10-N3). Figure 7 presents the peak $\mathrm{OH}^{*}$ signal against $\mathrm{X} / \mathrm{D}$ for various coflow conditions. Given the same coflow 


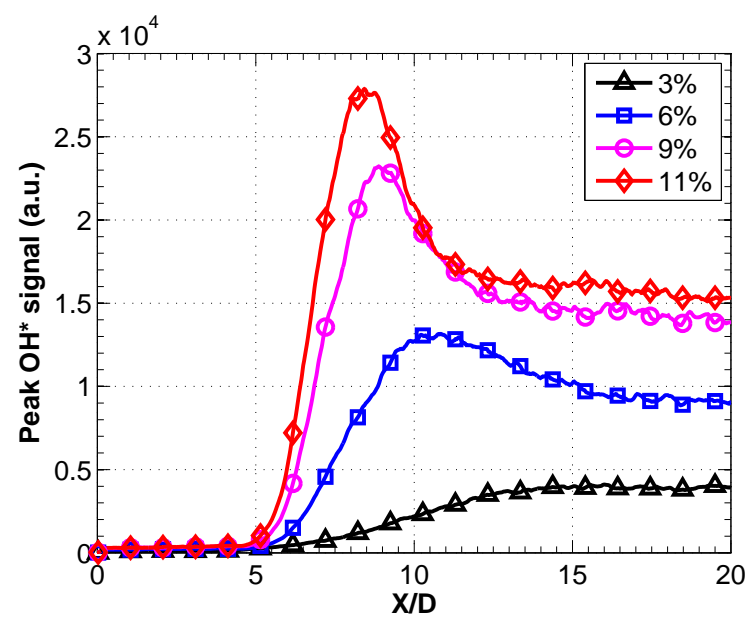

Figure 6: The peak $\mathrm{OH}^{*}$ signal from ethanol flames carried by air (F10-A1) as a function of X/D in the coflow with $3 \%$, $6 \%$, $9 \%$ and $11 \% \mathrm{O}_{2}$ by volume

condition, the intensity of $\mathrm{OH}^{*}$ chemiluminescence is higher when the flame is carried by air. In addition, the spatial gradient of $\mathrm{OH}^{*}$ in the axial direction is greater when carrier air is used instead of $\mathrm{N}_{2}$.

As described in section 3.1 the $\mathrm{OH}^{*}$ profile changes significantly with the coflow oxygen level. The intensity of $\mathrm{OH}^{*}$ chemiluminescence increases gradually with the axial distance in the $3 \% \mathrm{O}_{2}$ coflow, while a peak in $\mathrm{OH}^{*}$ is observed in the $6 \% \mathrm{O}_{2}$ coflow when air is used as a carrier gas. The peak in the $\mathrm{OH}^{*}$ intensity disappears when $\mathrm{N}_{2}$ is used as a carrier gas instead of air in the $6 \% \mathrm{O}_{2}$ coflow as shown in Figure 7 Despite the higher (6\%) coflow oxygen level, flames carried by $\mathrm{N}_{2}$ behaves closer to flames issuing into a $3 \%$ $\mathrm{O}_{2}$ coflow. Hence, the use of $\mathrm{N}_{2}$ as a carrier gas produces a similar impact to diluting the coflow, which also leads to a more uniform thermal field. The stoichiometric mixture fraction $\left(\mathrm{Z}_{s t}\right)$ is calculated to be 0.0706 for ethanol flames carried by $\mathrm{N}_{2}$ in a $6 \% \mathrm{O}_{2}$ coflow, while it is 0.0828 in the flames carried by air. It is suspected that the more uniform $\mathrm{OH}^{*}$ distribution is not only caused by the fuel dilution effect, but also caused by the actual changes in the flame structure, which will be discussed later. It is worth noting that the instantaneous $\mathrm{OH}^{*}$ images display the same trends mentioned above for the averaged images, despite the turbulent fluctuations in the flames.

\subsection{Impact of Jet Velocity}

To investigate the impact of jet velocity on lifted flames in a hot diluted coflow, experiments are performed using ethanol with two jet velocities in $9 \% \mathrm{O}_{2}$ coflow with the coflow temperature varying from $1250 \mathrm{~K}$ to 1385 K. Figure 8 shows ethanol flames carried by air at various coflow conditions with low (left:F10-A1) and high jet velocities (right:F30-A1). All the photographs are taken with an ISO sensitivity of 1600, exposure time of 4 seconds and an f-number of 16 . The low jet velocity is $44 \mathrm{~m} / \mathrm{s}$, while the high jet velocity is $112 \mathrm{~m} / \mathrm{s}$. The bulk jet Reynolds numbers for low velocity case and high velocity case are 10,000 and 30,000, respectively. The Reynolds number does not increase proportionally with the jet velocity as the CEM fails to maintain the jet temperature at $413 \mathrm{~K}$ due to the higher flow rate. All the ethanol flames shown here are blue in colour. No smoke or particulates are observed even in a 1385-K coflow during the experiments, suggesting 


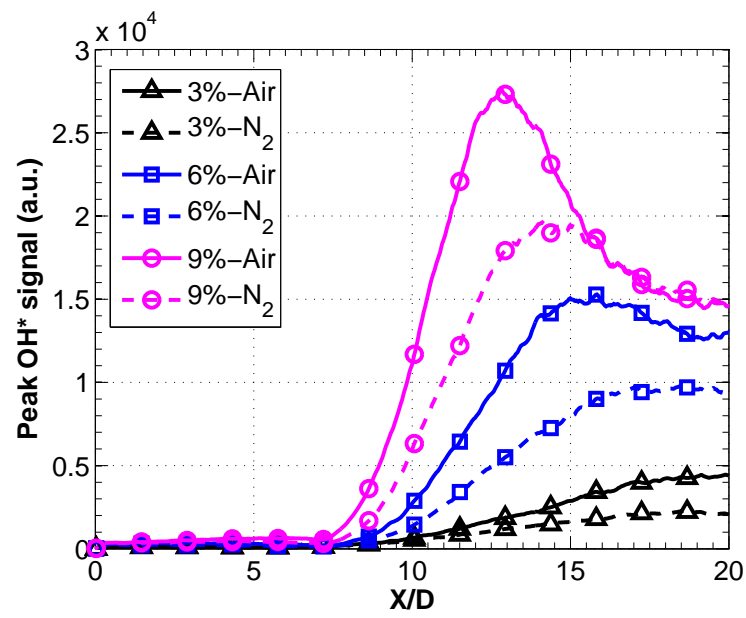

Figure 7: The peak $\mathrm{OH}^{*}$ signal from ethanol flames carried by air (F10-A3) or $\mathrm{N}_{2}$ (F10-N3) as a function of X/D in the coflow with $3 \%, 6 \%$ and $9 \% \mathrm{O}_{2}$ by volume.

a) $1250 \mathrm{~K}$

$\mathbf{X} / \mathbf{D}$

b) $1315 \mathrm{~K}$

$\mathbf{X} / \mathbf{D}$

c) $1385 \mathrm{~K}$
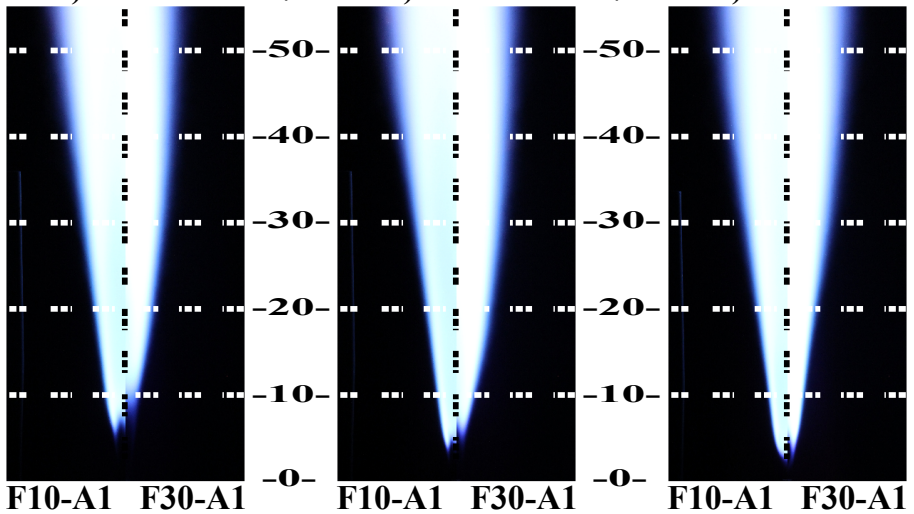

Figure 8: Photographs of ethanol flames carried by air with low (left:F10-A1) and high jet velocities (right:F30-A1) in 9\% $\mathrm{O}_{2}$ coflow with the coflow temperature varying from $1250 \mathrm{~K}$ to $1385 \mathrm{~K}$.

the absence of soot particulates. This is consistent with the MILD combustion characteristics, where the distributed reaction zone suppresses soot production. Neither the flame shape nor the luminosity changes with increasing jet velocity. Despite the much higher velocity, the liftoff heights do not change significantly either. Specifically, the ethanol flame in the $1250-\mathrm{K}$ coflow is slightly more visually lifted at the higher jet velocity, while the differences in the liftoff heights are negligible in the hotter coflows. A previous study on this burner with methane- and ethylene- based fuels has also reported minor impact of jet Reynolds number on the liftoff height [13.

The experimental results show an unusual relationship between liftoff heights and jet velocity/Reynolds number for flames in the JHC burner. For a cold-fuel-hot-oxidant configuration, a large body of work reported that autoignition occurs at the most reactive mixture fraction $\left(\mathrm{Z}_{M R}\right)$ instead of the stoichiometric mixture fraction [34. The existence of the most favourable mixture fraction $\mathrm{Z}_{M R}$ for combustion results from the balance between high temperature at low mixture fraction, and high fuel concentration at high mixture fraction [34]. The ignition delay time is largely determined by the minimum value of the scalar dissipation 
rate along the most-reactive isolevel, and the first ignition kernel always occurs at the position with the minimum scalar dissipation rate along this isolevel [35, 36]. The minimum scalar dissipation rate was found to be independent of the Reynolds number [35, 36]. Several competing effects on ignition are expected to happen at an increasing turbulence level. The autoignition can be prolonged due to higher mean scalar dissipation rates. However, a low local scalar dissipation rate is more likely to occur due to the enhanced fluctuation in the scalar dissipation rate 34]. Meanwhile, an enhanced mixing of reactants at the shear layer can accelerate the ignition [7]. The nearly constant lift-off heights at different jet Reynolds number are likely to be the combined results of all those possibilities due to the existence of the hot oxidiser.

\section{Discussion}

Experimental results suggest a transition from conventional combustion to MILD combustion as the coflow $\mathrm{O}_{2}$ mole fraction drops from $9 \%$ to $3 \%$. In order to identify the transition boundary with confidence, differences between these flames should be carefully examined according to the definitions and characteristics of MILD combustion.

As illustrated in Fig. 4 and Fig. 7, based on the "flameless" characteristic of MILD combustion, flames burning in a $3 \% \mathrm{O}_{2}$ hot coflow fit into the MILD combustion category, while flames burning in a $9 \% \mathrm{O}_{2}$ hot coflow do not. To better understand how coflow $\mathrm{O}_{2}$ level changes the intensity and distribution of $\mathrm{OH}^{*}$, laminar flame calculations are performed in Chemkin for ethanol flames carried by air fed toward a 1250-K oxidant flow with $3 \%-9 \% \mathrm{O}_{2}$. Figure 9 (a) shows the distribution of $\mathrm{OH}^{*}$ in mixture fraction space at a strain rate of $270 \mathrm{~s}^{-1}$, and ground-state $\mathrm{OH}$ is included for comparison. The location of peak $\mathrm{OH}$ is shifted to smaller mixture fraction with a reduced peak $\mathrm{OH}$ number density as the $\mathrm{O}_{2}$ level in the oxidant stream decreases. Interestingly, the peaks in $\mathrm{OH}$ number density for the three oxidant streams fall onto a straight line, as indicated by a thick dash-dot line.

Figure $9(\mathrm{~b})$ presents $\mathrm{Z}_{p O H}, \mathrm{Z}_{p O H^{*}}$, scaled peak temperature $\left(\mathrm{T}_{p}\right)$ and peak heat release rate $\left(\mathrm{H}_{p}\right)$ as a function of $\mathrm{Z}_{s t}$ for three oxidant streams. Given a more diluted oxidiser, $\mathrm{Z}_{s t}$ is shifted to smaller mixture fraction. Figure $9(\mathrm{~b})$ shows that the location of peak $\mathrm{OH}$ number density $\mathrm{Z}_{p O H}$ is linearly proportional to $\mathrm{Z}_{s t}$ for each oxidant stream, so is the location of peak $\mathrm{OH}^{*}$ number density $\mathrm{Z}_{p O H^{*}}$. However, the peak $\mathrm{OH}^{*}$ number density does not change linearly with the $\mathrm{O}_{2}$ level in the oxidant flow, as indicated by the thin dash-dot line in Fig. 9(a) The number density of $\mathrm{OH}^{*}$ reduces greatly with the $\mathrm{O}_{2}$ level decreasing from $6 \%$ to $3 \%$, which is in agreement with experimental results displayed in Fig. 7. Hence, the shift in $\mathrm{Z}_{p O H^{*}}$ is determined by the diluting effect on $\mathrm{Z}_{s t}$, while some factors other than that account for the change in the peak $\mathrm{OH}^{*}$ number density. As described in section $2.2 . \mathrm{OH}^{*}$ is closely related with temperature and heat release rate. Hence, the peak temperature and peak heat release rate, scaled to fit in one figure, are plotted against $Z_{s t}$ in Fig. 9(b) The decrease in the peak temperature is linear to the shift in $Z_{s t}$. However, the peak heat release in the $3 \% \mathrm{O}_{2}$ case does not fit onto the dash-dot line generated by the peak heat release rates in the $6 \%$ and $9 \% \mathrm{O}_{2}$ cases. Note that the gradient of the dash-dot line is almost identical to that of $\mathrm{Z}_{p O H^{*}}$. The overall net heat release rate is also found to decrease non-linearly as the oxidant stream becomes more diluted. The disproportional drop in the peak heat release rate and/or the overall net heat release rate could 


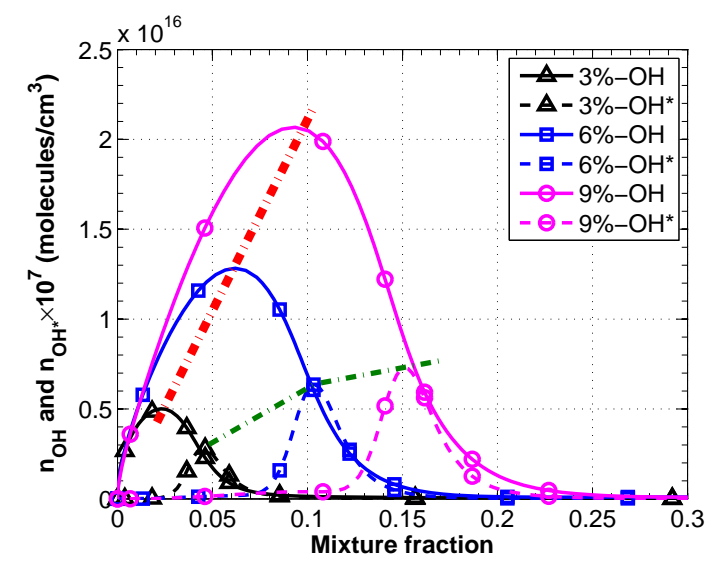

(a)

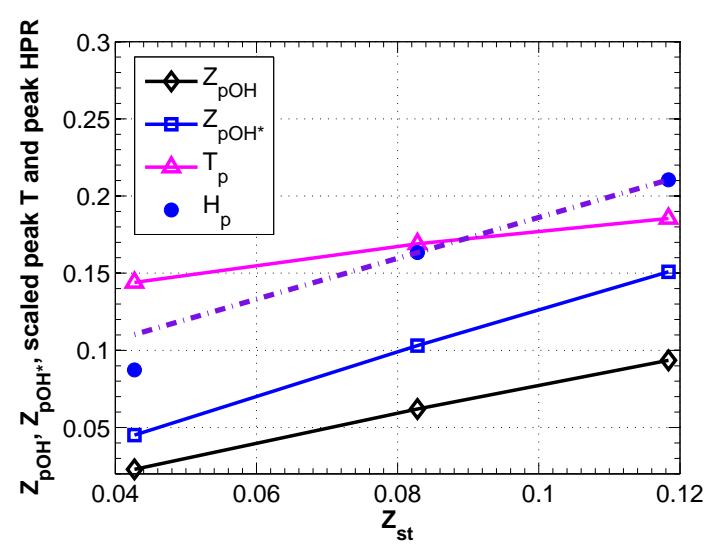

(b)

Figure 9: (a) Number density of $\mathrm{OH}^{*}$ (multiplied by $10^{7}$ ) and $\mathrm{OH}$ as a function of mixture fraction for ethanol flames in $1250-\mathrm{K}$ oxidisers with different $\mathrm{O}_{2}$ levels $\left(3 \%, 6 \%\right.$ and $9 \%$ ) (b) $\mathrm{Z}_{p O H}, \mathrm{Z}_{p O H^{*}}$, scaled peak temperature $\left(\mathrm{T}_{p}\right)$ and peak heat release rate $\left(\mathrm{H}_{p}\right)$ as a function of $\mathrm{Z}_{s t}$ for three oxidant streams. The dash-dot line is generated by the peak heat release rate in the $6 \%$ and $9 \% \mathrm{O}_{2}$ cases only.

be the cause of the "flameless" characteristics in MILD combustion, suggesting a need for threshold limits of them in defining MILD combustion regime.

In addition to the absence of visible flames, MILD combustion is characterised by a semi-uniform temperature distribution with low emissions of $\mathrm{NO}_{x}$ and soot in previous experimental studies [5, 7, 8, The suppression of soot precursors under MILD combustion conditions was suggested to associate with particular features in the heat release profile by de Joannon et al. [37. They performed numerical studies with OPPDIF code in the Chemkin software, in which MILD combustion of methane are simulated in three different configurations: Hot-Fuel-Diluted-Fuel, Hot-Oxidant-Diluted-Fuel and Hot-Diluted-Oxidant [37, 38, 39]. They identified MILD combustion regime in terms of heat release in mixture fraction space [38]. Two common signatures are associated with the MILD combustion in the three configurations. First, the fuel pyrolysis was suppressed at a high level of dilution, as indicated by the absence of a negative heat release region [38. In this pyrolytic region, endothermic reactions, such as methane decomposition or methyl radical recombination and dehydrogenation, exceed the oxidation reactions [39. The suppression of this pyrolytic region is of great importance as soot is most likely to form in this region in practical combustion appliances [40. Second, the location of the peak heat production rate $\left(Z_{h \max }\right)$ mismatched with the location of stoichiometric mixture fraction $\left(Z_{s t}\right)$ [38. They found that up to a certain level of fuel dilution, $Z_{h \max }$ was very close to $Z_{s t}$ [39]. Once the fuel dilution was beyond that particular limit, the heat production region started to shift backward toward the lean side [39. Hence, $Z_{h \max }$ shifted toward the lean side, meanwhile $Z_{s t}$ shifted towards the fuel rich side due to the fuel dilution [39. Notably, Hilbert and Thévenin [36] found that $Z_{h \max }$ corresponded to $\mathrm{Z}_{M R}$ at the ignition time in a counterflow system of hot air and cold hydrogen diluted in nitrogen, in both laminar and turbulent regime. Those MILD combustion characteristics reported by de Joannon et al. [37, 38, 39] are also applicable to n-heptane flames [41. It is interesting to see if those findings can be extrapolated to ethanol, therefore the boundary between MILD combustion and traditional combustion can 
be defined on the heat release profile only.

Laminar flame calculations for pure ethanol flames are performed with the fuel inlet temperature set to $413 \mathrm{~K}$. The oxidiser inlet is modelled as the $1250-\mathrm{K}$ experimental coflow with $3 \%, 6 \%$ and $9 \% \mathrm{O}_{2}$. The separation of the two inlets is $20 \mathrm{~mm}$, and the stagnation plane is at $10 \mathrm{~mm}$. The strain rate varies from $64 \mathrm{~s}^{-1}$ to $7400 \mathrm{~s}^{-1}$. Note that the impact of strain rate on the negative heat release region is considered in the present study, which has not been reported in literature.

Figure 10(a) shows the profiles of heat production rate for ethanol flames in the 1250-K oxidiser with $3 \% \mathrm{O}_{2}$ at three strain rates. Note that calculations are performed with a series of strain rates, three of which are presented here to represent typical heat production rate profiles. The heat production rate at the stoichiometric mixture fraction for each strain rate is marked with an asterisk on the line plots. At a strain rate of $64 \mathrm{~s}^{-1}$, a narrow oxidative region exists at the lean side, which is followed by a negative heat release region. A single peak heat release rate exists at a given strain rate. A mismatch of $Z_{h m a x}$ and $Z_{s t}$ is evident at the three strain rates, though the location of peak heat release is shifted to the fuel rich side at the highest strain rate, the underlying factors for which are not clear. On the lean side of $Z_{\text {hmax }}$, there exists an inflection point upon which the gradient of the curve changes. This inflection point becomes less apparent as the strain rate increases. Note that the negative heat release region caused by pyrolytic reactions is suppressed at higher strain rates. Particularly, the minimum heat release rate becomes zero at a strain rate of $131 \mathrm{~s}^{-1}$, which is referred to as the critical strain rate. The critical strain rate is much higher at the $6 \%$ and $9 \% \mathrm{O}_{2}$ level, however the general features remain the same. Those results at higher $\mathrm{O}_{2}$ levels are not presented here for brevity.

In order to have a full picture of the transition from conventional combustion to MILD combustion, the role of temperature is also taken into account in the laminar flame calculations. The temperature of the oxidiser investigated in the calculations ranges from $1250 \mathrm{~K}$ to $1550 \mathrm{~K}$. The two signatures in heat production rate profiles found by de Joannon et al. 38] are used to identify MILD combustion regime. Figure 10(b) shows the critical strain rate, where the transition from conventional combustion to MILD combustion happens, given a combination of temperature and $\mathrm{O}_{2}$ mole fraction in the oxidant stream. As the mismatch of $Z_{h \max }$ and $Z_{s t}$ is independent of strain rate, the critical strain rate is solely determined by the absence of a negative heat release region. Taking a $1250-\mathrm{K}$ oxidiser with $3 \% \mathrm{O}_{2}$ as an example, the critical strain rate is $131 \mathrm{~s}^{-1}$. Given a strain rate lower than $131 \mathrm{~s}^{-1}$, conventional combustion occurs. In contrast, MILD combustion takes place with a strain rate higher than that critical value. The critical strain rate for the negative heat release region to disappear increases with the temperature and $\mathrm{O}_{2}$ level of the oxidiser. Particularly, at the high $\mathrm{O}_{2}$ level, the required strain rate to diminish the negative heat release region increases substantially with the temperature of the oxidiser varying from $1400 \mathrm{~K}$ to $1550 \mathrm{~K}$. However, for ethanol flame in the oxidant stream with $3 \% \mathrm{O}_{2}$, MILD combustion can be achieved with relatively moderate strain rate even at a temperature of $1550 \mathrm{~K}$.

Experimental results in section 3.3 show that the jet Reynolds number has negligible impact on the apparent lift-off height and luminosity of flames in $9 \% \mathrm{O}_{2}$ coflow with various temperature, which seems to differ from results provided by laminar flame calculations. Taking flames in the $9 \% \mathrm{O}_{2}$ 1250-K oxidant stream 


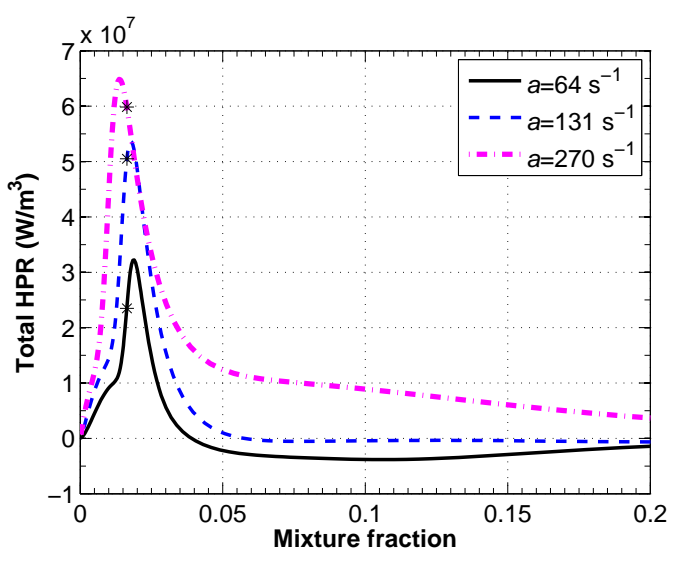

(a) $\mathrm{X}_{\mathrm{O}_{2}}=3 \%$

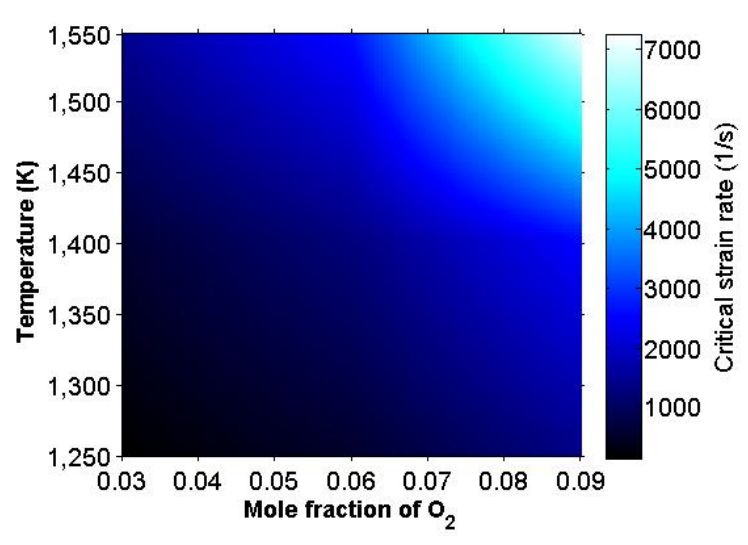

(b) Critical strain rate

Figure 10: (a) Heat production rate profiles of ethanol flames in a $1250-\mathrm{K}$ oxidiser with $3 \% \mathrm{O}_{2}$ : The heat production rate at the stoichiometric mixture fraction is marked with an asterisk; (b) The critical strain rate required for the transition from conventional combustion to MILD combustion to occur in a given oxidant stream.

as an example, calculations show that a negative heat release region still exists as the strain rate increases from $64 \mathrm{~s}^{-1}$ to $1200 \mathrm{~s}^{-1}$, which is an almost 20 -fold increase. However, the jet Reynolds numbers only ranges from 10,000 to 30,000 in current experiments. It is suspected that the jet Reynolds numbers in the current experiments correspond to strain rates within a small range, which is not sufficient to make a difference.

Figure 10(b) demonstrates that the absence of a negative heat release region is strain rate dependent at a given temperature and $\mathrm{O}_{2}$ mole fraction of the oxidant stream. To understand the impact of strain rate on the heat production, a brief analysis on the ethanol chemistry is essential. In ethanol-air combustion, $\mathrm{CH}_{3} \mathrm{CH}_{2} \mathrm{OH}$ is first converted to three $\mathrm{C}_{2} \mathrm{H}_{5} \mathrm{O}$ isomers via $\mathrm{H}$-atom abstraction reactions, including $\mathrm{CH}_{3} \mathrm{CH}_{2} \mathrm{O}$, $\mathrm{CH}_{2} \mathrm{CH}_{2} \mathrm{OH}$, and $\mathrm{CH}_{3} \mathrm{CHOH}$ [26]. Most of the three isomers are oxidised to $\mathrm{CH}_{3} \mathrm{HCO}$, and then further oxidised to $\mathrm{CO}$ or $\mathrm{CO}_{2}$ [26]. Besides oxidation, the pyrolysis of ethanol generally occurs at the coexistence of low local oxygen concentration and high temperature. During the pyrolysis, ethanol is decomposed to smaller hydrocarbons in the absence of oxygen, which removes heat from the system. A preliminary analysis is performed to identify key contributing reactions to the total heat release rate, taking ethanol flames in a 1250-K oxidiser with $3 \% \mathrm{O}_{2}$ as an example. One of the major contributors identified among all the endothermic reactions is the reaction $\mathrm{CH}_{3} \mathrm{CH}_{2} \mathrm{OH}(+\mathrm{M}) \rightleftharpoons \mathrm{CH}_{3}+\mathrm{CH}_{2} \mathrm{OH}(+\mathrm{M})$. Figure 11(a) shows that the heat subtraction from the decomposition of $\mathrm{CH}_{3} \mathrm{CH}_{2} \mathrm{OH}$ initially increases, then decreases with the strain rate. At a higher strain rate, the residence time is reduced, meanwhile the reactants are supplied to the reaction zone at a faster rate. The non-linear relationship between the heat subtraction from this reaction and strain rate is suspected to result from these two competing factors. Of the exothermic reactions, the most striking trend is found in reaction $\mathrm{CH}_{3} \mathrm{CHOH}+\mathrm{O}_{2} \rightleftharpoons \mathrm{CH}_{3} \mathrm{HCO}+\mathrm{HO}_{2}$ as illustrated in Fig. 11(b), There is a six-fold increase in the heat addition from the oxidation of $\mathrm{CH}_{3} \mathrm{CHOH}$ with strain rate increasing from $64 \mathrm{~s}^{-1}$ to $270 \mathrm{~s}^{-1}$. It is understood that the strong increase in the heat addition from this reaction overcompensates the heat subtraction, which explains the absence of a negative heat release region at a higher strain rate. 


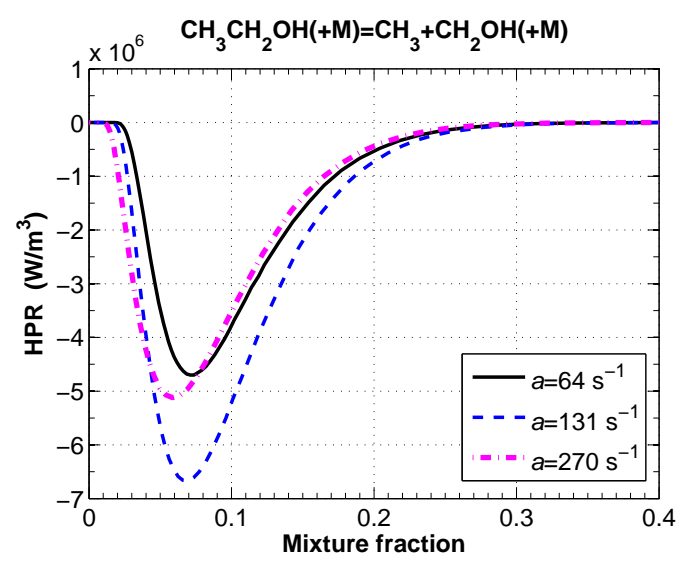

(a) Endothermic

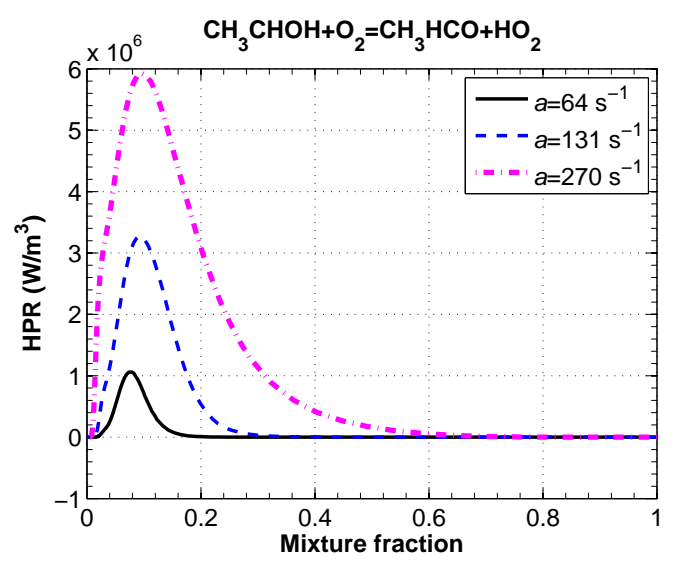

(b) Exothermic

Figure 11: Heat production rate profiles of particular reactions for ethanol flames in a $1250-\mathrm{K}_{\text {oxidiser }}$ with $3 \% \mathrm{O}_{2}$

The significant increase in this reaction is suspected to result from an enhanced transportation of $\mathrm{O}_{2}$ across the reaction zone at a higher strain rate, particularly at a low coflow $\mathrm{O}_{2}$ level [21], which is confirmed by the calculation of mass flux of $\mathrm{O}_{2}$ at these strain rates.

Figure 10(b) demonstrates that, at low strain rates, the negative heat release region is more likely to disappear as the $\mathrm{O}_{2}$ level in the oxidant stream decreases. This is because the reaction $\mathrm{CH}_{3} \mathrm{CH}_{2} \mathrm{OH}(+\mathrm{M})$ $\rightleftharpoons \mathrm{CH}_{3}+\mathrm{CH}_{2} \mathrm{OH}(+\mathrm{M})$ is greatly suppressed at a lower $\mathrm{O}_{2}$ level, which is shown in Fig. 12 As mentioned previously, the occurrence of fuel pyrolysis requires the coexistence of low local oxygen concentration and high temperature. Hence, there are two possible reasons for the depression of fuel pyrolysis in the oxidant stream with $3 \% \mathrm{O}_{2}$ : low temperature and/or increased availability/concentration of $\mathrm{O}_{2}$.

Figure 12 shows that reaction $\mathrm{CH}_{3} \mathrm{CH}_{2} \mathrm{OH}(+\mathrm{M}) \rightleftharpoons \mathrm{CH}_{3}+\mathrm{CH}_{2} \mathrm{OH}(+\mathrm{M})$ initiates at around $\mathrm{Z}=0.4$ for the oxidant stream with $9 \% \mathrm{O}_{2}$, at which the flame temperature is around $1100 \mathrm{~K}$ as indicated by Fig. 13(a) This reaction only starts at $\mathrm{Z}=0.2$ for the oxidiser with $3 \% \mathrm{O}_{2}$ due to lower flame temperature.

Comparing to the distribution of $\mathrm{OH}$ in mixture fraction space as shown in Fig. 15, laminar flame calculations reveal that this reaction mostly takes place on the fuel-rich side of the reaction zone. Figure 13(b) shows the concentration of $\mathrm{O}_{2}$ for three oxidisers in the range of interest. The concentration of $\mathrm{O}_{2}$ on the fuel-rich side in the $3 \%$ case is higher than that in the $6 \%$ and $9 \%$ case despite a lower initial $\mathrm{O}_{2}$ concentration in the oxidiser. The $\mathrm{O}_{2}$ concentration on the fuel-rich side results from two competing factors: the consumption of $\mathrm{O}_{2}$ and the transportation of $\mathrm{O}_{2}$ across the reaction zone 21. Calculations reveal that the mass flux of $\mathrm{O}_{2}$ on the fuel-rich side of the reaction zone is higher in the $3 \% \mathrm{O}_{2}$ stream than that in the $9 \%$ $\mathrm{O}_{2}$ stream as shown in Fig. 15 . The lower consumption rate of $\mathrm{O}_{2}$ in the $3 \% \mathrm{O}_{2}$ stream, resulted from a lower system reactivity, also contributes to the higher local $\mathrm{O}_{2}$ concentration as reported in a previous study [21]. Hence, the combined effects of low temperature and higher local concentration of $\mathrm{O}_{2}$ greatly suppresses the fuel pyrolysis in the oxidant stream with $3 \% \mathrm{O}_{2}$. MILD combustion is characterised with low soot emissions [7, 8], which essentially requires the suppression of this pyrolytic region. This makes ethanol flames in the oxidiser with $3 \% \mathrm{O}_{2}$ more likely to fall into the MILD combustion category. 


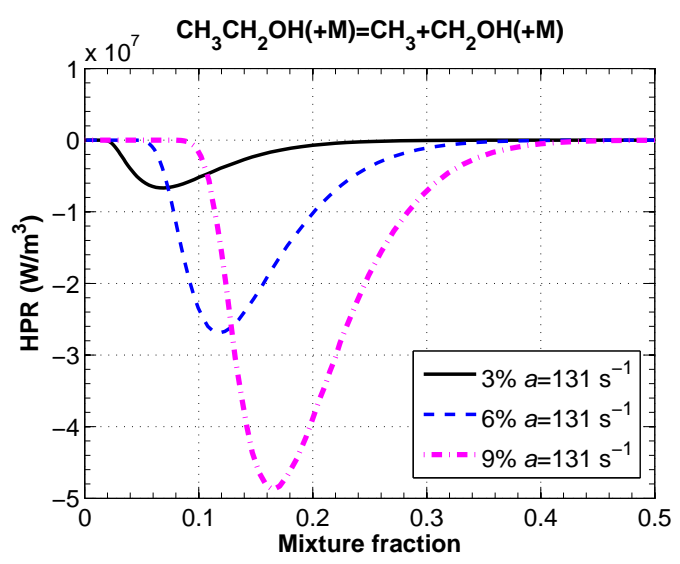

Figure 12: Heat production rate profile for ethanol decomposition as a function of mixture fraction at three oxidant streams

Imaging of $\mathrm{OH}^{*}$ chemiluminescence revealed that the use of $\mathrm{N}_{2}$ as a carrier gas produces a more uniform distribution of $\mathrm{OH}^{*}$, which makes flames in a $6 \% \mathrm{O}_{2}$ coflow behave more like flames in a $3 \% \mathrm{O}_{2}$ coflow. It is interesting to investigate the impact of carrier gas on the heat production rate profile, particularly on the absence of a negative heat release region. Parametric studies are performed for pure ethanol flames (no dilution), ethanol diluted with pure $\mathrm{N}_{2}$, and ethanol diluted with pure $\mathrm{O}_{2}$ in a 1250-K oxidiser with $3 \% \mathrm{O}_{2}$ in the Chemkin software. To directly compare the oxidiser with the inert, $\mathrm{O}_{2}$ is used to mix with ethanol instead of air. Laminar flame calculations are performed for various amounts of carrier gas and strain rates. It should be noted that these conditions are not the same as the experiments, however they are chosen to exacerbate the effects of carrier gas/fuel dilution. At low strain rates, a negative heat release region exists when ethanol is not mixed with carrier gas. When ethanol is mixed with carrier gas, this negative heat release region starts to disappear as the amount of $\mathrm{N}_{2}$ or $\mathrm{O}_{2}$ in the fuel stream increases. For example, at a strain rate of $64 \mathrm{~s}^{-1}$, in order to make the minimum heat release rate non-negative, the mole fraction of $\mathrm{O}_{2}$ in the fuel stream should be greater than 0.3 when ethanol is mixed with pure $\mathrm{O}_{2}$. As for ethanol diluted with pure $\mathrm{N}_{2}$, a mole fraction of $\mathrm{N}_{2}$ greater than 0.7 is required to diminish the negative heat release region. The heat production rate profiles for the pure ethanol flame $\left(\mathrm{X}_{\mathrm{EtOH}}=1\right)$, ethanol mixed with $\mathrm{N}_{2}\left(\mathrm{X}_{\mathrm{N}_{2}}=0.7\right.$, $\left.\mathrm{X}_{\mathrm{EtOH}}=0.3\right)$, and ethanol mixed with $\mathrm{O}_{2}\left(\mathrm{X}_{\mathrm{O}_{2}}=0.3, \mathrm{X}_{\mathrm{EtOH}}=0.7\right)$ at a strain rate of $64 \mathrm{~s}^{-1}$ are shown in Figure 14(a) To explain the absence of a negative heat release region in those cases, heat subtraction from ethanol decomposition is investigated due to its importance. As shown in Fig. 14(b), heat subtraction from ethanol decomposition is lowered when ethanol is diluted with $\mathrm{N}_{2}$, which is likely to result from lower flame temperature. The heat subtraction from the decomposition of ethanol, shifting to a richer region, is greatly increased when $\mathrm{O}_{2}$ is mixed with ethanol. Comparing the total heat production rate profile with the profile for ethanol decomposition, it is clear that this reaction takes place within the strong oxidative region at the fuel rich side. Hence the heat subtraction from ethanol decomposition is overtaken by the heat release from oxidative reactions when ethanol is diluted with $\mathrm{O}_{2}$. In addition, Fig. 16 shows that for ethanol mixed with $\mathrm{O}_{2}$ case, ethanol is largely consumed at $\mathrm{Z}>0.2$, which is consistent with the location of ethanol decomposition in this case (see Fig. 14(b)).

The heat production rate profile changes significantly when ethanol is diluted with $\mathrm{O}_{2}$. A wide oxidative 


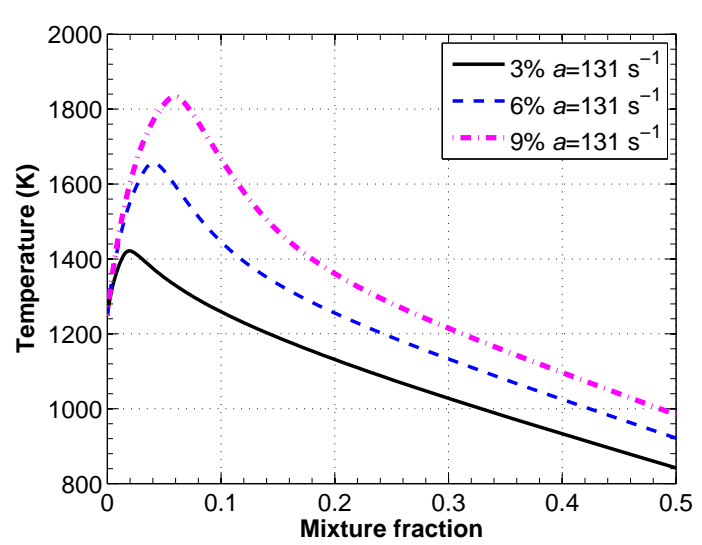

(a) Temperature

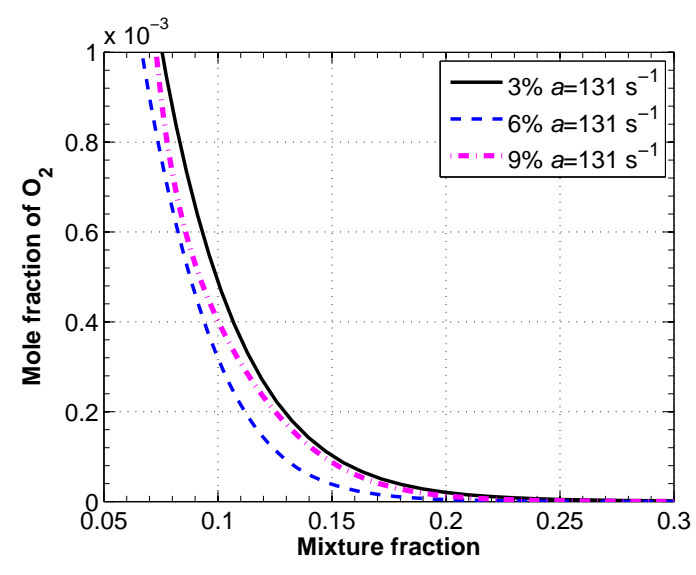

(b) Mole fraction of $\mathrm{O}_{2}$

Figure 13: Temperature and mole fraction of $\mathrm{O}_{2}$ as a function of mixture fraction at three oxidant streams

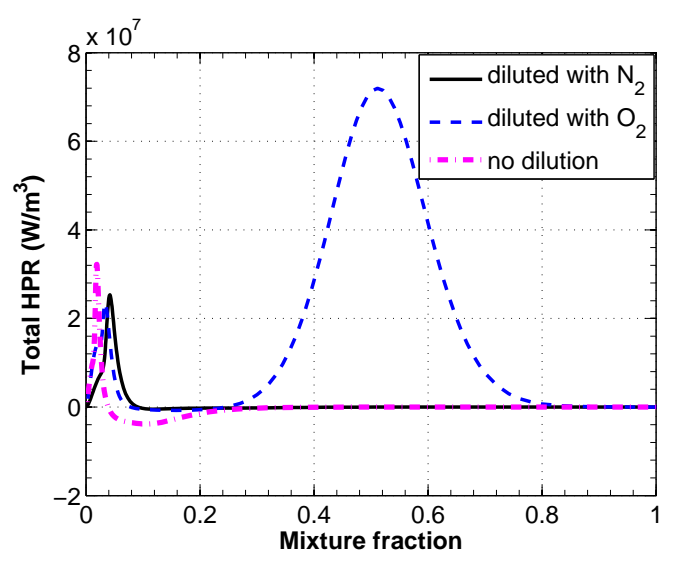

(a) Total HPR

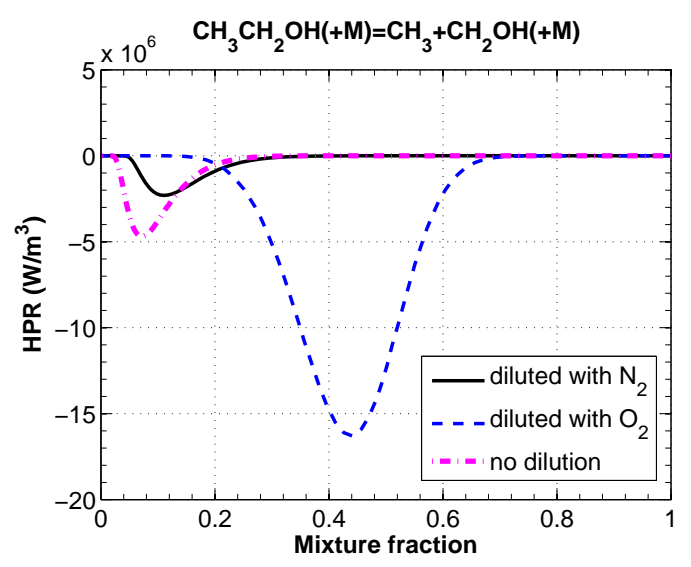

(b) Ethanol decomposition

Figure 14: Heat production rate profiles as a function of mixture fraction for three cases: pure ethanol flames (no dilution), ethanol diluted with pure $\mathrm{N}_{2}$, and ethanol diluted with pure $\mathrm{O}_{2}$ in a $1250-\mathrm{K}$ oxidiser with $3 \% \mathrm{O}_{2}$.

region exists at the fuel rich side due to the existence of $\mathrm{O}_{2}$ in the fuel stream, which contributes to most of the heat release. A narrow oxidative region exists at $\mathrm{Z}<0.1$, the shape of which is similar to that for ethanol mixed with $\mathrm{N}_{2}$. In addition to two heat-release regions, Fig. 17 demonstrates that $\mathrm{OH}$ exists at $0 \leq \mathrm{Z} \leq 0.05$ and $0.2 \leq \mathrm{Z} \leq 0.8$, suggesting the existence of a double-reaction zone when ethanol is mixed with $\mathrm{O}_{2}$. Previous work 21] has shown that the enhanced $\mathrm{O}_{2}$ diffusion towards the fuel-rich side through "reaction zone weakening" is a key feature of MILD combustion flames, leading to an increasing formation of important intermediates. The build-up of those intermediates is responsible for the stabilization of the flames [21]. Figure 17 suggests that adding $\mathrm{O}_{2}$ to the fuel stream directly also produces this effect. 


\section{Conclusions}

The present paper was focused on the transition of prevaporised ethanol flames from conventional combustion to MILD combustion. Ethanol flames in the $3 \% \mathrm{O}_{2}$ coflow appear "flameless" in the region controlled by coflow such that the flame base is difficult to identify. Imaging of $\mathrm{OH}^{*}$ chemiluminescence shows that the spatial gradient and the peak in the $\mathrm{OH}^{*}$ signal profile are significantly reduced in the $3 \% \mathrm{O}_{2}$ coflow, indicating a more uniform distribution of heat release and temperature. The use of $\mathrm{N}_{2}$ as a carrier gas renders the $\mathrm{OH}^{*}$ profile for the $6 \% \mathrm{O}_{2}$ coflow case similar to that of ethanol flame carried by air in the $3 \% \mathrm{O}_{2}$ coflow. Experimental results suggest a transition from conventional combustion to MILD combustion with the decrease of coflow $\mathrm{O}_{2}$ level or the use of $\mathrm{N}_{2}$ as a carrier gas. In order to clarify this transition, a series of laminar flame calculations are performed to examine the flame structure in details. Several key findings are summarised as follows:

- The location of peak $\mathrm{OH}^{*}$ in mixture fraction space is shifted proportionally to the $\mathrm{O}_{2}$ level in the oxidant stream as it is determined by the shift in $\mathrm{Z}_{s t}$. However, the change in the peak $\mathrm{OH}^{*}$ number density is not linear with the $\mathrm{O}_{2}$ level, which might result from the disproportional change in the peak heat release rate and/or the overall net heat release rate. This suggests a need to define threshold limits of them to achieve "flameless" MILD combustion.

- The absence of a negative heat release region is used to identify MILD combustion regime. The negative heat release region is more likely to disappear at a higher strain rate given a constant $\mathrm{O}_{2}$ level in the oxidiser. The main reason for this is that the transportation of $\mathrm{O}_{2}$ across the reaction zone is enhanced at a higher strain rate, which promotes the oxidative reactions instead of fuel decomposition.

- At relatively low strain rates, the negative heat release region has a higher potential to disappear at a low $\mathrm{O}_{2}$ level in the oxidant flow. In comparison to the oxidant streams with $6 \%$ and $9 \% \mathrm{O}_{2}$, a combined effect of lower flame temperature and higher local concentration of $\mathrm{O}_{2}$ is found to inhibit the decomposition of ethanol at the $3 \% \mathrm{O}_{2}$ oxidant stream.

- The impact of carrier gas on the presence/absence of a negative heat release region is investigated. It is found that using either $\mathrm{O}_{2}$ or $\mathrm{N}_{2}$ as a carrier gas helps to diminish the negative heat release region, and more $\mathrm{N}_{2}$ is needed to achieve the same result. The absence of a negative heat release region is believed to result from lower flame temperature when $\mathrm{N}_{2}$ is used as a carrier gas. When $\mathrm{O}_{2}$ is used, a strong oxidation on the fuel rich side overtakes the endothermic reactions, diminishing the negative heat release region.

\section{Acknowledgements}

This research is funded by the China Scholarship Council and The University of Adelaide through a joint postgraduate scholarship. Funding from the Australian Research Council (ARC) and United States Air Force Asian Office of Aerospace Research and Development (AOARD) is gratefully acknowledged. 


\section{References}

[1] J. Wünning, J. Wünning, Flameless oxidation to reduce thermal NO-formation, Prog. Energ. Combust. 23 (1) (1997) 81-94.

[2] R. Weber, S. Orsino, N. Lallemant, A. Verlaan, Combustion of natural gas with high-temperature air and large quantities of flue gas, Proc. Combust. Inst. 28 (1) (2000) 1315-1321.

[3] B. B. Dally, S. H. Shim, R. A. Craig, P. J. Ashman, G. G. Szeg, On the burning of sawdust in a MILD combustion furnace, Energy Fuels 24 (6) (2010) 3462-3470.

[4] C. Galletti, A. Parente, M. Derudi, R. Rota, L. Tognotti, Numerical and experimental analysis of (NO) emissions from a lab-scale burner fed with hydrogen-enriched fuels and operating in mild combustion, Int. J. Hydrogen Energ. 34 (19) (2009) 8339-8351.

[5] M. Saha, B. B. Dally, P. R. Medwell, E. M. Cleary, Moderate or intense low oxygen dilution (MILD) combustion characteristics of pulverized coal in a self-recuperative furnace, Energy Fuels 28 (9) (2014) 6046-6057.

[6] A. Rao, Y. Levy, A new combustion methodology for low emission gas turbine engines, in: 8th International Symposium on High Temperature Air Combustion and Gasification, Poznań, Poland, 2010, pp. $177-185$.

[7] P. R. Medwell, P. A. M. Kalt, B. B. Dally, Imaging of diluted turbulent ethylene flames stabilized on a jet in hot coflow (JHC) burner, Combust. Flame 152 (1) (2008) 100-113.

[8] M. Derudi, R. Rota, Experimental study of the mild combustion of liquid hydrocarbons, Proc. Combust. Inst. 33 (2) (2011) 3325-3332.

[9] B. B. Dally, A. N. Karpetis, R. S. Barlow, Structure of turbulent non-premixed jet flames in a diluted hot coflow, Proc. Combust. Inst. 29 (1) (2002) 1147-1154.

[10] E. Oldenhof, M. Tummers, E. Van Veen, D. Roekaerts, Ignition kernel formation and lift-off behaviour of jet-in-hot-coflow flames, Combust. Flame 157 (6) (2010) 1167-1178.

[11] E. Oldenhof, M. Tummers, E. Van Veen, D. Roekaerts, Role of entrainment in the stabilisation of jet-in-hot-coflow flames, Combust. Flame 158 (8) (2011) 1553-1563.

[12] R. Cabra, J. Y. Chen, R. W. Dibble, A. N. Karpetis, R. S. Barlow, Lifted methane-air jet flames in a vitiated coflow, Combust. Flame 143 (4) (2005) 491-506.

[13] P. R. Medwell, B. B. Dally, Experimental observation of lifted flames in a heated and diluted coflow, Energy Fuels 26 (9) (2012) 5519-5527.

[14] R. L. Gordon, A. R. Masri, E. Mastorakos, Simultaneous Rayleigh temperature, $\mathrm{OH}$-and $\mathrm{CH}_{2} \mathrm{O}-\mathrm{LIF}$ imaging of methane jets in a vitiated coflow, Combust. Flame 155 (1) (2008) 181-195. 
[15] J. Sidey, E. Mastorakos, R. Gordon, Simulations of Autoignition and Laminar Premixed Flames in Methane/Air Mixtures Diluted with Hot Products, Combust. Sci. Technol. 186 (4-5) (2014) 453-465.

[16] A. H. Lefebvre, D. R. Ballal, Gas Turbine Combustion : Alternative Fuels and Emissions, Hoboken : Taylor and Francis, 2010.

[17] H. C. Rodrigues, M. J. Tummers, E. H. van Veen, D. J. Roekaerts, Spray flame structure in conventional and hot-diluted combustion regime, Combust. Flame 162 (3) (2015) 759-773.

[18] S. H. Stårner, J. Gounder, A. R. Masri, Effects of turbulence and carrier fluid on simple, turbulent spray jet flames, Combust. Flame 143 (4) (2005) 420-432.

[19] W. O'Loughlin, A. R. Masri, The structure of the auto-ignition region of turbulent dilute methanol sprays issuing in a vitiated co-flow, Flow Turbul. Combust. 89 (1) (2012) 13-35.

[20] J. Ye, P. R. Medwell, E. Varea, S. Kruse, B. B. Dally, H. G. Pitsch, An experimental study on MILD combustion of prevaporised liquid fuels, Appl. Energy 151 (2015) 93-101.

[21] P. R. Medwell, P. A. M. Kalt, B. B. Dally, Reaction zone weakening effects under hot and diluted oxidant stream conditions, Combust. Sci. Technol. 181 (7) (2009) 937-953.

[22] S. H. Stårner, R. Bilger, M. Long, J. Frank, D. Marran, Scalar dissipation measurements in turbulent jet diffusion flames of air diluted methane and hydrogen, Combustion science and technology 129 (1-6) (1997) 141-163.

[23] R. Lückerath, W. Meier, M. Aigner, FLOX ${ }^{\circledR}$ combustion at high pressure with different fuel compositions, J. Eng. Gas Turb. Power 130 (1) (2008) 011505.

[24] J. Lee, D. Santavicca, Experimental diagnostics for the study of combustion instabilities in lean premixed combustors, J. Propul. Power 19 (5) (2003) 735-750.

[25] L. C. Haber, U. Vandsburger, W. R. Saunders, V. K. Khanna, An examination of the relationship between chemiluminescent light emissions and heat release rate under non-adiabatic conditions, in: ASME Turbo Expo 2000: Power for Land, Sea, and Air, American Society of Mechanical Engineers, 2000, pp. V002T02A041-V002T02A041.

[26] N. M. Marinov, A detailed chemical kinetic model for high temperature ethanol oxidation, Int. J. Chem. Kinet. 31 (1999) 183-220.

[27] C. Panoutsos, Y. Hardalupas, A. Taylor, Numerical evaluation of equivalence ratio measurement using $\mathrm{OH}^{*}$ and $\mathrm{CH}^{*}$ chemiluminescence in premixed and non-premixed methane-air flames, Combust. Flame 156 (2) (2009) 273-291.

[28] J. M. Hall, E. L. Petersen, An optimized kinetics model for $\mathrm{OH}$ chemiluminescence at high temperatures and atmospheric pressures, Int. J. Chem. Kinet. 38 (12) (2006) 714-724. 
[29] M. De Leo, A. Saveliev, L. A. Kennedy, S. A. Zelepouga, OH and CH luminescence in opposed flow methane oxy-flames, Combust. Flame 149 (4) (2007) 435-447.

[30] J. A. Sidey, E. Mastorakos, Simulations of laminar non-premixed flames of methane with hot combustion products as oxidiser, Combust. Flame 163 (2015) 1-11.

[31] J. Sidey, E. Mastorakos, Visualization of MILD combustion from jets in cross-flow, Proc. Combust. Inst. 35 (3) (2015) 3537-3545.

[32] P. R. Medwell, P. A. M. Kalt, B. B. Dally, Simultaneous imaging of OH, formaldehyde, and temperature of turbulent nonpremixed jet flames in a heated and diluted coflow, Combust. Flame 148 (1) (2007) $48-61$.

[33] B. Dally, E. Riesmeier, N. Peters, Effect of fuel mixture on moderate and intense low oxygen dilution combustion, Combust. Flame 137 (4) (2004) 418-431.

[34] E. Mastorakos, Ignition of turbulent non-premixed flames, Prog. Energ. Combust. 35 (1) (2009) 57-97.

[35] E. Mastorakos, T. Baritaud, T. Poinsot, Numerical simulations of autoignition in turbulent mixing flows, Combust. Flame 109 (1) (1997) 198-223.

[36] R. Hilbert, D. Thévenin, Autoignition of turbulent non-premixed flames investigated using direct numerical simulations, Combust. Flame 128 (1) (2002) 22-37.

[37] M. de Joannon, P. Sabia, G. Cozzolino, G. Sorrentino, A. Cavaliere, Pyrolitic and Oxidative Structures in Hot Oxidant Diluted Oxidant (HODO) MILD Combustion, Combust. Sci. Technol. 184 (7-8) (2012) $1207-1218$.

[38] M. de Joannon, P. Sabia, G. Sorrentino, A. Cavaliere, Numerical study of mild combustion in hot diluted diffusion ignition (HDDI) regime, Proc. Combust. Inst. 32 (2) (2009) 3147-3154.

[39] M. de Joannon, G. Sorrentino, A. Cavaliere, MILD combustion in diffusion-controlled regimes of hot diluted fuel, Combust. Flame 159 (5) (2012) 1832-1839.

[40] C. Esarte, M. Peg, M. P. Ruiz, A. Millera, R. Bilbao, M. U. Alzueta, Pyrolysis of ethanol: gas and soot products formed, Industrial \& Engineering Chemistry Research 50 (8) (2011) 4412-4419.

[41] M. de Joannon, P. Sabia, A. Cavaliere, Alternative ignition systems, ProcessEng Engineering GmbH, 2009, Ch. HDDI mild combustion, pp. 133-150. 